\title{
Biosynthesis of $\gamma$-Polyglutamic Acid by Bacillus licheniformis Through Submerged Fermentation (SmF) and Solid-state Fermentation (SSF)
}

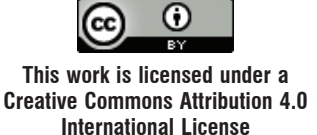
International License

\section{Campos, ${ }^{\text {a, }}{ }^{,}$R. M. Kaspary, ${ }^{\text {a }}$ M. J. Rossi, ${ }^{b}$ and}

\section{T. A. M. Medeiros ${ }^{\mathrm{a}}$}

${ }^{a}$ São Paulo State University (Unesp), Institute of Science and Technology, Sorocaba/SP/Brazil

${ }^{b}$ Federal University of Santa Catarina, Department of Microbiology, Immunology and Parasitology, Florianópolis/SC/Brazil

doi: https://doi.org/10.15255/CABEQ.2021.1921

Original scientific paper Received: January 26, 2021

Accepted: July 28, 2021

Gamma-Polyglutamic acid ( $\gamma$-PGA) was produced from fermentation processes by inoculating the bacterium Bacillus licheniformis on different substrates. In submerged fermentation $(\mathrm{SmF})$, glycerol and glucose were used as the main carbon substrates while ammonium sulfate served to provide nitrogen. In solid-state fermentation (SSF), soybean was used as the main substrate. Tests carried out in an airlift bioreactor with $B$. licheniformis showed a maximum productivity of $0.789 \mathrm{~g} \mathrm{~L}^{-1} \mathrm{~h}^{-1}$ and a yield of $0.4 \mathrm{~g} \mathrm{~g}^{-1}$. Different soybean cultivars from the 2015 and 2016 crops were used in the SSF. The BRS 1001IPRO cultivar, from the 2016 crop, showed the highest production, i.e., $1.2 \mathrm{~g} \mathrm{~L}^{-1}$ of $\gamma$-PGA. This cultivar was subjected to different levels of milling (fine, intermediate and coarse). Coarsely milled grains increased $\gamma$-PGA production to $2.7 \mathrm{~g} \mathrm{~L}^{-1}$. Moreover, coarse milling made the internal nutrients of the grains available for fermentation and this particle size did not compromise aeration during fermentation.

Keywords:

$\gamma$-polyglutamic acid, biosynthesis, B. licheniformis, SmF, SSF

\section{Introduction}

The industrial importance of bioprocessing and bioprospecting of microorganisms cannot be overstated. In recent decades, in addition to basic nutrition functions, food has been found to possess other functional properties that benefit the chemical and pharmaceutical industry, and more recently, that have been applied to the treatment of waste and effluents. The use of compounds made from biodegradable polymers of vegetable or microbial origin is extremely important from the standpoint of saving resources. Since such biodegradable polymers are of natural origin, they can be incorporated into the natural carbon cycle, which involves natural recycling.

The use of renewable sources in the production of consumer goods offers substantial socioeconomic and environmental benefits. The final destination of soybeans must go beyond oil and bran processing, extending its use to different sectors of the economy. The development of a bioprocess to produce bioactive compounds is of interest to environmental and human health, reducing the generation of sludge from water treatment plants, and hence, of

${ }^{*}$ Corresponding author: E-mail: v.campos@unesp.br aluminum concentrations that contribute to Alzheimer's disease.

Brazil is the world's biggest soybean producer; hence, the production of $\gamma$-PGA in fermented soy substrate shows a very promising potential to add economic and technological value to commodities, as well as future research. $\gamma$-PGA is naturally present in products of fermented soybean mucilage consumed in Asian countries, and soy and its derivatives are therefore potential substrates for the production of biopolymer. Thus, glycerol considered a by-product in the production of biodiesel from soy, can be an inexpensive source of nutrients to produce $\gamma$-PGA.

Soybean bagasse, which is also a by-product of the biodiesel extraction process, still contains quantities of nutrients that serve as food sources for many microorganisms, thereby producing new compounds. $\gamma$-PGA is produced from carbon and nitrogen-based nutrients that are present in soybeans. Therefore, it is important to know the variations in cultivars in order to select the best properties for conversion in the fermentation process.

Since $\gamma$-PGA has various biochemical properties, this polymer can perform different functions, depending on the organism and the environment ${ }^{1,2}$. 
The limitation of $\gamma$-PGA production due to the increase in the viscosity of liquid culture media and the search for cheaper substrates have led to the development of solid-state fermentation (SSF) processes. However, reports on the production of $\gamma$-PGA in SSF are much less frequent than those in submerged fermentation, e.g., the works of $\mathrm{Oh}^{3}$, $\mathrm{Xu}^{4}$, and $\mathrm{Chen}^{5,6}$. Worldwide interest in these polymers has grown considerably in recent times ${ }^{7}$. Although their application is advantageous for environmental conservation, their high production cost compared to that of conventional products for treating water and effluents is still a major disadvantage. This can be exemplified by comparing the cost of aluminum sulfate - US\$ $1.10 / \mathrm{kg}$, and aluminum polychloride - US\$ $7.50 / \mathrm{kg}$, against that of $30 \%$ $\gamma$-PGA - US\$ $32.00 / \mathrm{kg}$ and pure $\gamma$-PGA - US\$ $620.00 / \mathrm{kg}$.

Biopolymers appear as a substitute for conventional products traditionally used in the market ${ }^{8,9}$. Some companies produce $\gamma$-PGA commercially for different sectors of the economy. Shandong Freda Biotechnology Co. Ltd., a biotechnology company, produces, extracts, and sells $\gamma$-PGA products for the food industry, cosmetics, health care, water treatment, hygiene products, medical applications, etc. Nippon PolyGlu Co. Ltd. produces PGa21Ca for water treatment ${ }^{10} \cdot \gamma$-PGA is considered a superior bioflocculant because of its ability to flocculate a wide range of organic and inorganic compounds ${ }^{11}$.

$\gamma$-PGA can be extracted from natto, a fermented soybean food produced and consumed mainly in Japan. Natto, which has an odor characteristic of short-chain fatty acids and ammonia, is composed of a highly viscous polymer. In bacterial biosynthesis, glutamic acid, the monomer that constitutes $\gamma$-PGA, may be exogenous or endogenous, i.e., it can be supplied to the microorganisms in culture media or through the Krebs cycle. Various carbon sources can be used for the synthesis of $\gamma$-PGA, such as glucose and citric acid. Through glycolysis and the Krebs cycle, these carbons will synthesize $\alpha$-ketoglutaric acid, which is a key intermediate for the synthesis of $\gamma$-PGA, which is a direct precursor of glutamic acid ${ }^{12}$. Another route to produce glutamic acid is from glutamine, which involves synthesizing glutamic acid by means of the enzyme glutaminase $^{13,14} \cdot \gamma$-PGA is produced predominantly by bacteria belonging to Bacillus spp., such as $B$. licheniformis, B. subtilis, B. megaterium, B. pumilus, B. mojavensis, and B. amyloliquefaciens. B. licheniformis and $B$. subtilis have been used mostly for the fermentative production of $\gamma-\mathrm{PGA}^{11}$.

Bacillus licheniformis, which is the object of this study, is used industrially because of its ability to secrete large amounts of enzymes in the culture medium, and because it is a producer of important compounds, such as $\gamma$-PGA ${ }^{11,15,16}$. B. licheniformis can also be used as an expression platform for enzymes, amino acids, antibiotics, biofuels, and other secondary metabolites ${ }^{17,18}$. B. licheniformis has been qualified as a producer of antimicrobial peptides, with activity against several pathogenic or deteriorating microorganisms.

The main purpose of this work was to study the process of $\gamma$-PGA production from $B$. licheniformis by means of SmF and SSF. In parallel, the 2015 and 2016 soybean crops were tested to measure their protein content, and hence, their greater production of $\gamma$-PGA. This study highlights the relevance and appropriate use of biomass for the development of bioproducts.

\section{Materials and methods}

The Bacillus licheniformis strain NCTC 10341 used in this research was donated by the Oswaldo Cruz Foundation (Fiocruz), Rio de Janeiro, Brazil.

Three soybean cultivars developed by the Brazilian Agricultural Research Corporation (EMBRAPA), namely, BRS 232, BRS $360 \mathrm{RR}$, and BRS 1001 IPRO, were used to produce $\gamma$-PGA via SSF. The harvested soybeans were subjected to no chemical or biological treatments. In order to ensure reproducible results, cultivars were used from two different crops, 2015 and 2016. The soybeans were processed in a Willey knife mill and sifted through 16-mesh (fine fraction), 9-mesh (medium fraction), and 4-mesh (coarse fraction) sieves.

The glycerol used in this study, a by-product of the soybean biodiesel extraction process, resulting from the transesterification of biodiesel, was provided by IGTPAN - Granado Polyacrylonitrile Technology Institute.

The standard used here was $\gamma$-PGA in sodium salt form, a product of Merck. The solutions used in all the experiments were prepared using analytical grade reagents and ultrapure water from a Millipore Milli-Q water purification system.

The materials were characterized using methods such as elemental analysis and infrared spectroscopy. Elements commonly found in organic compounds, such as carbon, hydrogen, and nitrogen, were identified by means of elemental analysis, using a Perkin Elmer $2400 \mathrm{CHNS} / \mathrm{O}$ elemental analyzer.

The starting and modified samples were mounted on metal stub holders and coated with gold. The soybean cultivar BRS 1001 IPRO was then subjected to electron detection in a LEO 440i SEM coupled to an Oxford Si(Li) X-ray Energy Dispersive Spectrometer. 
The presence of $\gamma$-PGA functional groups was investigated by means of infrared spectroscopy. The infrared spectra from the compounds embedded in potassium bromide for IR spectroscopy were obtained in the range of $4000-400 \mathrm{~cm}^{-1}$, using a Perkin Elmer 16 PC FTIR spectrophotometer and Agilent Cary 660.

The glucose concentration was determined by the GOD-Trinder enzymatic oxidase method ${ }^{19}$. The glycerol kinase colorimetric assay was performed following the method described by Huang ${ }^{20}$.

The amount of $\gamma$-PGA was determined by the spectrophotometric method based on the complex reaction of $\gamma$-PGA with cetyltrimethylammonium bromide (CTAB), as described by Kanno and Takamatsu $^{21}$. The aqueous solution of $\gamma$-PGA $(300 \mu \mathrm{L})$ was mixed with phosphate buffer and CTAB $(0.1$ $\mathrm{M} / \mathrm{NaCl} 1 \mathrm{M}$ ), and held in ultrasonic bath at a temperature of $30{ }^{\circ} \mathrm{C}$ for $25 \mathrm{~min}$. The $\gamma$-PGA concentration was determined by measuring the turbidity of the mixture with the spectrophotometer at $400 \mathrm{~nm}$, and comparing this with a standard curve. The calibration curve was constructed from complexation with CTAB. Turbidity based calibration curve $(y=0.0079 x+0.0001$, where $x$ and $y$ represent the concentration of $\gamma$-PGA and the turbidity at $400 \mathrm{~nm}$ of the mixtures) gave a good linearity over a range of at least $4.0-40 \mathrm{mg} \mathrm{L}^{-1} \gamma$-PGA. Moisture and volatiles were quantified using the American Oil Chemists Society (AOCS) method Bc 2-4922. Ash content was determined by AOCS method 945.38C, while total lipids were determined using the AOCS method Ac 3-4422. The protein content was determined using Method 037 of the Adolfo Lutz Institute $^{23}$.

\section{Experimental}

\section{Microorganism}

Bacillus licheniformis strain NCTC 10341, donated by Fiocruz, was used for the production of $\gamma$-PGA. The ideal medium to grow this strain is in nutrient broth at a temperature of $33{ }^{\circ} \mathrm{C}$ and $\mathrm{pH}$ between 6.8 and 7.2. The recommended incubation time for aerobic culture was $24 \mathrm{~h}$.

Strips containing $B$. licheniformis spores were placed in a sterile medium, and incubated at $33{ }^{\circ} \mathrm{C}$ for 48 hours under orbital shaking at $150 \mathrm{rpm}$. Aliquots were centrifuged, supplemented with sterile glycerol $(20 \% \mathrm{v} / \mathrm{v})$, and stored at $25^{\circ} \mathrm{C}$.

The culture media were sterilized in an autoclave at $121{ }^{\circ} \mathrm{C}$ for 15 minutes. The sugars were sterilized separately and added before inoculation to prevent the precipitation of ions such as iron, manganese, and zinc. Sterilization can affect the availability of carbohydrates, which may react with am- monium ions and amino acids that are present in solutions for the production of $\gamma$-PGA.

The medium for the production of $\gamma$-PGA via $\mathrm{SmF}$ in an airlift bioreactor was composed of $\left(\mathrm{g} \mathrm{L}^{-1}\right)$ : glucose 30; glycerol 30; L-glutamic acid 50; citric acid 10; $\mathrm{NH}_{4} \mathrm{NO}_{3} \quad 8 ; \mathrm{NH}_{4} \mathrm{SO}_{4} \quad 8 ; \mathrm{K}_{2} \mathrm{HPO}_{4} \quad$ 2; $\mathrm{MgSO}_{4} \cdot 7 \mathrm{H}_{2} \mathrm{O} 0.1 ; 0.03 \mathrm{MnSO}_{4}$ and $0.3 \%$ n-heptane.

\section{Submerged fermentation $(\mathrm{SmF})$ in an airlift bioreactor}

In this work, we used an external-loop airlift bioreactor, which allowed for greater customization of the connections, the ascending gas-liquid flow in the riser, and the descending flow in the downcomer. Airlift bioreactors are pneumatically agitated reactors equipped with simple, compact, low-cost, and easy-to-operate devices. In addition to presenting high rates of mass transfer and low energy consumption, another advantage of airlift bioreactors is that they can be used for culturing microorganisms with minimal mechanical impact. According to $\mathrm{Rossi}^{24}$, the use of an airlift bioreactor with forced air injection enables recirculation of the liquid medium. This recirculation also generates turbulence and mixing, contributing significantly to mass transfer in the system. The greater distance covered by the gas bubbles while passing through the system without the inconvenient agitation of turbines favors good transfer of oxygen, ensuring the integrity of the cells due to low shear stress.

The 2.3-L capacity airlift bioreactor used here had external circulation. The bioreactor was sterilized internally with a $3 \%$ peracetic acid solution. After removing the sterilization solution, the bioreactor was sealed until the inoculated culture medium was added, whereupon the fermentation process began. The $\mathrm{pH}$ level was adjusted to 7.0 and kept constant throughout fermentation. Oxygen content was monitored with a polarographic probe, and air flow was regulated manually in order to keep the dissolved oxygen (DO) above a critical concentration of $10 \%$ saturation. The second step consisted of feeding nutrients, i.e., glycerol, glucose, calcium chloride, and zinc sulfate, into the bioreactor. Tests in the bioreactor were conducted as described by Kumar and $\mathrm{Pal}^{25}$ and Yoon et al. ${ }^{26}$, by inoculating $46 \mathrm{~mL}$ of $B$. licheniformis $(2 \% \mathrm{v} / \mathrm{v})$ in $2.3 \mathrm{~L}$ of sterilized culture medium in an autoclave. The $\mathrm{pH}$ level was kept stable between 6.8 and 7.2 in a controller containing solutions for automatic adjustment, with the addition of $0.2 \mathrm{M} \mathrm{NaOH}$ and $0.1 \mathrm{M}$ $\mathrm{H}_{2} \mathrm{SO}_{4}$ solutions.

The temperature in the bioreactor was controlled by circulating water in a heat exchanger in the downcomer, using a thermostatic bath. The inlet air was produced by compressed air, purified with 


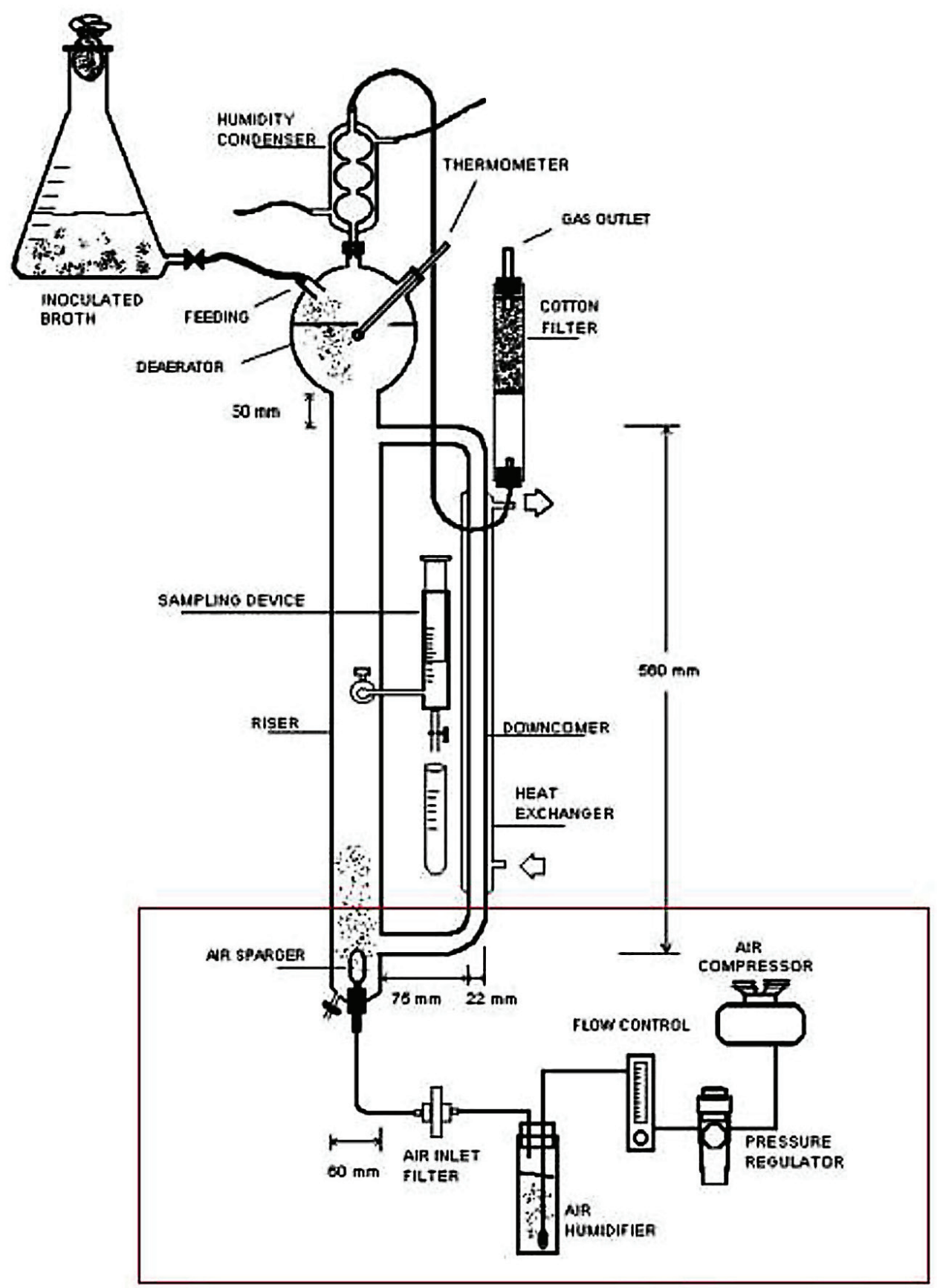

Fig. 1 - Airlift bioreactor system and inlet air flow control

the aid of PTFE (polytetrafluoroethylene) hydrophobic filter membranes with $0.22 \mathrm{~mm}$ diameter pores. Airflow and pressure were controlled manually, as shown in the schematic diagram in Fig. $1^{27}$. The bioreactor was also equipped with a diffuser to reduce the size of bubbles, a porous ceramic sparger at the base of the riser, from which $10 \mathrm{~mL}$ aliquots were removed to analyze $\gamma$-PGA, without the need to stop the process and with less risk of contamination. The glucose and glycerol solutions used in the medium for the inoculation and production of $\gamma$-PGA were sterilized separately and incorporated into the medium prior to inoculation.
Solid-state fermentation (SSF) using soy as substrate

$\gamma$-PGA was produced in triplicate with $B$. licheniformis in three cultivars, and the values were expressed as means \pm standard deviation. The tests were carried out in a 250-mL Erlenmeyer flask, with a hydrophobic cotton plug and gauze. The soybeans were milled in a Wiley mill, and sifted through 16 mesh (fine fraction), 9 mesh (medium fraction), and 4 mesh (coarse fraction) Tyler sieves.

Ten grams of soybeans (dry weight) were selected, immersed in water $(\mathrm{pH} 7.0)$ to obtain an ini- 
Table 1 -Coded and original values used in the CCRD to evaluate the effect of the initial moisture content, inoculum volume, amount of substrate and temperature in the production of $\gamma-P G A$ by $S S F$

\begin{tabular}{l|c|c|c|c|c}
\hline \multicolumn{1}{c|}{ Variable } & -2 & -1 & 0 & +1 & +2 \\
\hline Initial moisture content $(\%)$ & 40 & 45 & 50 & 55 & 60 \\
Inoculum volume (\%) & 10 & 15 & 20 & 25 & 30 \\
Amount of substrate $(\mathrm{g})$ & 5 & 10 & 15 & 20 & 25 \\
Temperature $\left({ }^{\circ} \mathrm{C}\right)$ & 31 & 33 & 35 & 37 & 39 \\
\hline
\end{tabular}

tial moisture content of the substrate of $60 \%$, and then stored at $10{ }^{\circ} \mathrm{C}$ for $18 \mathrm{~h}$, using a modified version of the procedure proposed by Kiuchi and Watanabe ${ }^{28}$. The grains were then autoclaved for 1 hour at $130{ }^{\circ} \mathrm{C}$, and cooled to $50{ }^{\circ} \mathrm{C}$ prior to inoculation (patent $\mathrm{CN} 1718735 \mathrm{~B})$. The inoculum, at a concentration of $10 \%(\mathrm{~m} / \mathrm{v})$, was spread over the surface of the substrate under aseptic conditions, and then subjected to static incubation at $33{ }^{\circ} \mathrm{C}$ for $48 \mathrm{~h}$, using a modified procedure described by $\mathrm{Chen}^{5}$. To interrupt the fermentation process, the mixture was refrigerated for eight hours at a temperature of 3 to $10{ }^{\circ} \mathrm{C}$, with low moisture content ${ }^{28}$.

Upon completion of the fermentation, $30 \mathrm{~mL}$ of deionized water was added to $10 \mathrm{~g}$ of fermented substrates in the Erlenmeyer flask. After agitating at $200 \mathrm{rpm}$ and $28{ }^{\circ} \mathrm{C}$ for $1 \mathrm{~h}$ on a rotary shaker ${ }^{28}$, the mixture was filtered through muslin cloth and centrifuged at $14800 \mathrm{rpm}$ for $20 \mathrm{~min}$. Then, $300 \mu \mathrm{L}$ of the supernatant was poured into four volumes of cold methanol to precipitate the $\gamma$-PGA. The sediment was collected by centrifugation at $14800 \mathrm{rpm}$ for $20 \mathrm{~min}$, and redissolved with $300 \mu \mathrm{L}$ of deionized water. To obtain a clarified aqueous solution of $\gamma$-PGA, any insoluble contaminants were removed by centrifugation at $14800 \mathrm{rpm}$ for $20 \mathrm{~min}^{30,31}$.

To maximize the production of $\gamma$-PGA in SSF, factors such as initial moisture content, inoculum volume, substrate quantity, and temperature were evaluated. Tests for the four factors were performed according to the Central Composite Rotatable Design (CCRD), totaling 31 tests with seven repetitions at the central point. The values were determined using Minitab software. Table 1 shows the coded and original values of the factors. The $\mathrm{pH}$ level of the substrates was adjusted to 7.0, and all the substrates were incubated for 48 hours in static mode.

\section{Results and discussion}

\section{Production of $y$-PGA in an airlift bioreactor}

According to $\mathrm{Hsueh}^{32}, \gamma$-PGA is biosynthesized only at the beginning of the stationary phase, which is explained by the limited availability or even lack of nutrients needed for the growth of Bacillus cells. The resulting biopolymer is degraded at the end of the stationary phase, especially when basic carbon and nitrogen substrates are scanty. The concentration of carbon source and the ideal concentration of nitrogen are essential for bacterial growth, considering the formation of product with amine groups, where an adequate $\mathrm{C} / \mathrm{N}$ ratio in the environment is crucial to ensure a good yield, preventing the formation of undesirable by-products.

In the airlift system, glycerol was used as the main carbon source because of its favorable organic composition and the fact that it is part of the Krebs cycle, where part of the reactions of biopolymer formation occur. In the process by inoculation of $B$. licheniformis conducted in a $\mathrm{SmF}$ according to the methodology described by Yoon ${ }^{25}, 35.0 \mathrm{~g} \mathrm{~L}^{-1}$ was obtained, while the production with $B$. subtilis was $31.7 \mathrm{~g} \mathrm{~L}^{-1}$ following the same methodology also described by $\mathrm{Wu}^{33}$ with glycerol as substrate in submerge medium. According to $\mathrm{Wu}^{33}$, the addition of glycerol contributed to increase productivity and reduce viscosity, mainly when the process was carried out with $B$. licheniformis. The authors emphasized the importance of adding fractionated glycerol to enable the microorganism to make the best possible of the substrate, thereby increasing its molecular weight.

In the first experiment, the $\mathrm{pH}$ and $\mathrm{DO}$ were controlled (Fig. 2), and $15.21 \mathrm{~g} \mathrm{~L}^{-1}$ of biopolymer was produced in only 19 hours of fermentation. The production yield reached $21.31 \mathrm{~g} \mathrm{~L}^{-1} 27$ hours after the beginning of the process, when the glycerol and glycoside substrates were depleted and the minimum saturation of DO occurred, with a productivity of $0.789 \mathrm{~g} \mathrm{~L}^{-1} \mathrm{~h}^{-1}$. The temperature was kept at $35^{\circ} \mathrm{C}$, the $\mathrm{pH}$ level was adjusted to 7.0, and automatically corrected using $0.2 \mathrm{M}$ of $\mathrm{NaOH}$ or $0.1 \mathrm{M}^{\circ} \mathrm{H}_{2} \mathrm{SO}_{4}$, to remain between 6.8 and 7.2.

After 30 hours, a new test was carried out; this time to investigate $\gamma$-PGA productivity through the addition of carbon and enzyme inducers. In this process, $20 \%$ of the medium of the previous test was maintained, keeping the (active and inactive) microorganisms present in the medium. The new culture medium was prepared in the same conditions as those used previously, but with lower concentrations of carbon substrates. The medium was composed of $\left(\mathrm{g} \mathrm{L}^{-1}\right)$ : glucose 15; glycerol 15; L-glutamic acid 25; citric acid 5; $\mathrm{NH}_{4} \mathrm{NO}_{3} 4 ; \mathrm{NH}_{4} \mathrm{SO}_{4} 4$; $\mathrm{K}_{2} \mathrm{HPO}_{4} 1 ; \mathrm{MgSO}_{4} \cdot 7 \mathrm{H}_{2} \mathrm{O} 0.05 ; 0.015 \mathrm{MnSO}_{4}$ and $0.3 \%$ n-heptane.

Fig. 3 shows the production of $20.30 \mathrm{~g} \mathrm{~L}^{-1}$ after $43 \mathrm{~h}$ of fermentation and the addition of substrates (7.5 $\mathrm{g} \mathrm{L}^{-1}$ of glycerol and $6.0 \mathrm{~g} \mathrm{~L}^{-1}$ of glucose). In this reaction, there was a decrease in DO saturation (Fig. 3). The residual glucose in this range was 


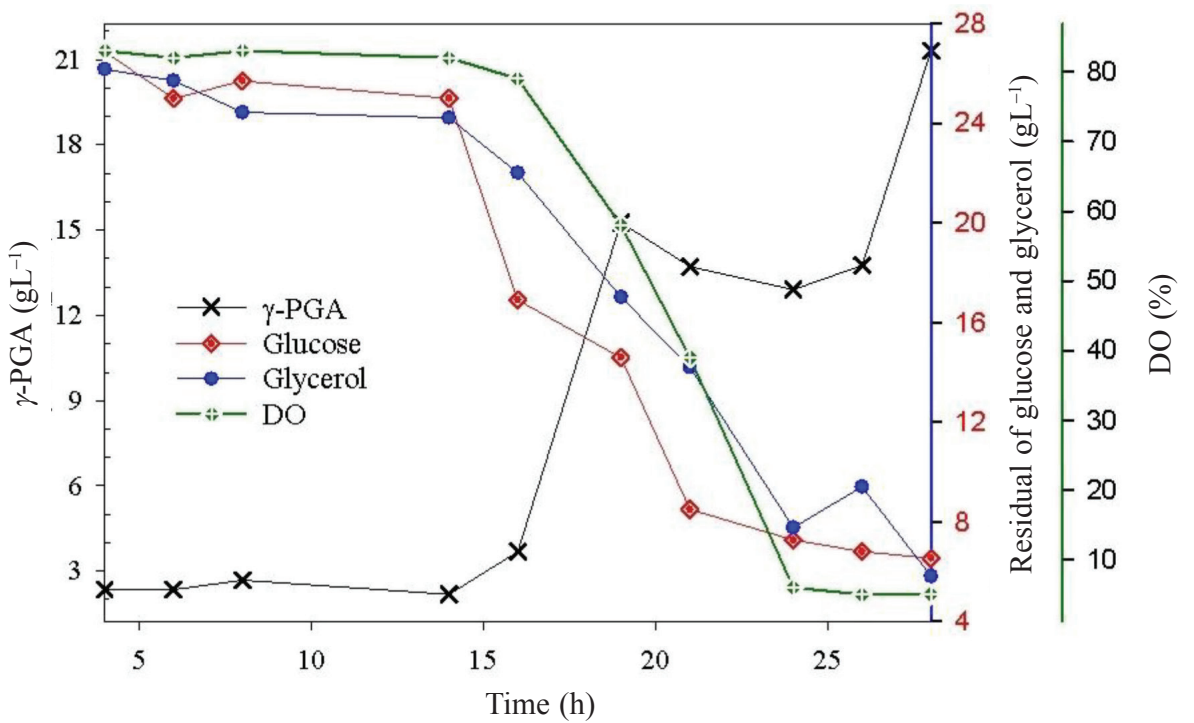

Fig. $2-\gamma$-PGA production and carbon source consumption, and oxygen consumption in an airlift bioreactor

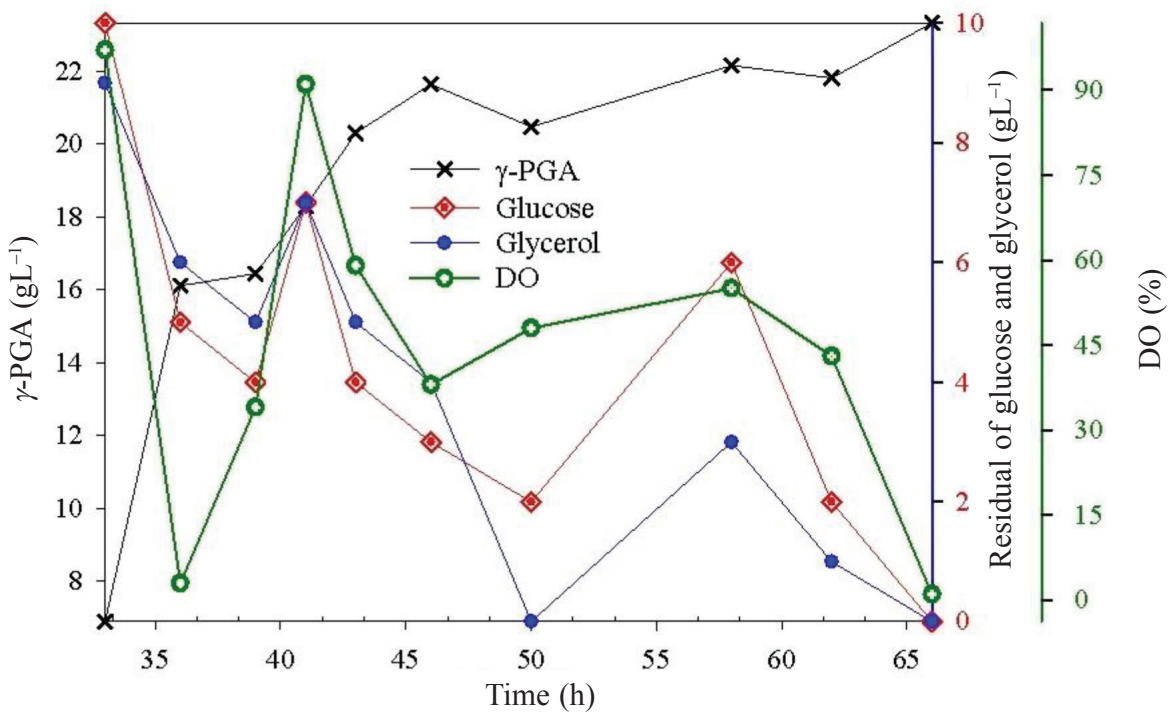

Fig. $3-\gamma$-PGA production and carbon source consumption, and oxygen consumption

$4 \mathrm{~g} \mathrm{~L}^{-1}$ and glycerol $5 \mathrm{~g} \mathrm{~L}^{-1}$. With the addition of 50 $\mathrm{mL}$ of $1 \mathrm{~g} \mathrm{~L}^{-1}$ of the inducers calcium chloride and zinc sulfate, maximum production $\left(23.32 \mathrm{~g} \mathrm{~L}^{-1}\right)$ was achieved in 66 hours, yielding $0.4 \mathrm{~g} \mathrm{~g}^{-1} \gamma$-PGA of carbon substrate. $\gamma$-PGA production has been widely studied in different bioreactors, mainly in liquid media. However, what stands out in the current study is the combined use of nutrient sources, particularly of carbon and inducers, as well as cofactors inherent to the airlift bioreactor system. This study can be further expanded.

Table 2 presents the production, productivity, and yield obtained in the tests with different nutrient concentrations. Note the productivity in the airlift bioreactor, where oxygen is more available to microorganisms. Also note the $\gamma$-PGA production yield considering the limitation of nutrients and their addition according to the consumption by $B$. licheniformis. This prevents an overload of carbon sources and the production of undesirable intermediates. Moreover, agitation is produced by the flow of filtered air, reducing the risk of contamination of the medium. An important point about this system is the need to control the parameters of the process, particularly DO, which is essential in aerobic cultures, and a limiting factor for the growth of Bacillus spp.

\section{Production of $y$-PGA in solid-state fermentation}

Using the parameter of rainfall as a determinant revealed that the 2015 and 2016 soybean crops varied in terms of their proximate composition. The cultivars BRS 232, BRS 1001 IPRO, and BRS 360 RR 
Table 2 -Production, productivity and yield obtained in tests with different concentrations of nutrients in this study compared to the literature

\begin{tabular}{|c|c|c|c|c|c|c|}
\hline Strain & Nutrient & Time $(\mathrm{h})$ & $\begin{array}{c}\text { Production } \\
\gamma \text {-PGA } \\
\left(\mathrm{g} \mathrm{L}^{-1}\right)\end{array}$ & $\begin{array}{c}\text { Productivity } \\
\gamma \text {-PGA } \\
\left(\mathrm{g} \mathrm{L}^{-1} \mathrm{~h}^{-1}\right)\end{array}$ & $\begin{array}{c}\text { Yield } \\
\left(\mathrm{g} \mathrm{g}^{-1}\right)\end{array}$ & Ref. \\
\hline B. subtilis $\mathrm{NX}-2$ & Glycerol & $48 \mathrm{~h}$ & 31.7 & 0.66 & 0.264 & {$[33]$} \\
\hline B. licheniformis ATCC 9445A & Glutamic acid and citric acid & $42 \mathrm{~h}$ & 35 & 0.83 & 0.188 & {$[26]$} \\
\hline B. licheniformis NCTC 10341 & Glutamic acid glucose and glycerol & $27 \mathrm{~h}$ & 21.31 & 0.79 & 0.178 & This study (SmF) \\
\hline B. licheniformis NCTC 10341 & Glucose and glycerol & $66 \mathrm{~h}$ & 23.32 & 0.36 & 0.462 & This study (SmF) \\
\hline
\end{tabular}

Table 3 - Proximate composition of three different soybean cultivars $\left(g 100 \mathrm{~g}^{-1}\right)$ from the 2015 and $2016 \mathrm{crop}$

\begin{tabular}{cccccccc}
\hline \multicolumn{2}{c}{ Cultivar } & Moisture and volatiles & Protein $(\mathrm{Nx6.5})^{1}$ & Total lipids & Carbohydrate $_{(\mathrm{t})}$ & Ash \\
\hline \multirow{2}{*}{ BRS 232 } & 2015 & $12.82(0.15)^{\mathrm{a}}$ & $33.66(0.04)^{\mathrm{a}}$ & $20.64(0.19)^{\mathrm{a}}$ & 28.16 & $4.72(0.01)^{\mathrm{a}}$ \\
& 2016 & $9.05(0.15)^{\mathrm{a}}$ & $36.90(0.13)^{\mathrm{a}}$ & $21.33(0.08)^{\mathrm{a}}$ & 28.14 & $4.58(0.04)^{\mathrm{a}}$ \\
\multirow{2}{*}{ BRS 360 } & 2015 & $13.42(0.26)^{\mathrm{a}}$ & $30.60(0.03)^{\mathrm{a}}$ & $21.31(0.08)^{\mathrm{a}}$ & 29.33 & $5.34(0.04)^{\mathrm{a}}$ \\
& 2016 & $8.95(0.03)^{\mathrm{a}}$ & $38.49(0.06)^{\mathrm{a}}$ & $20.86(0.18)^{\mathrm{a}}$ & 26.92 & $4.78(0.04)^{\mathrm{a}}$ \\
BRS & 2015 & $13.34(0.28)^{\mathrm{a}}$ & $34.07(0.09)^{\mathrm{a}}$ & $21.73(0.18)^{\mathrm{a}}$ & 26.39 & $4.47(0.03)^{\mathrm{a}}$ \\
1001 & 2016 & $9.92(0.18)^{\mathrm{a}}$ & $35.98(0.43)^{\mathrm{a}}$ & $21.32(0.10)^{\mathrm{a}}$ & 28.24 & $4.54(0.02)^{\mathrm{a}}$ \\
\hline
\end{tabular}

${ }^{1}$ The protein content of the sample is calculated by multiplying the total nitrogen content by a specific factor for converting nitrogen to protein. ${ }^{a}$ Mean and estimated standard deviation.

presented a total rainfall of 762,749 , and $461 \mathrm{~mm}$, respectively, in the 2015 crop, and of 1452, 1023, and $1023 \mathrm{~mm}$, respectively, in the 2016 crop. The increase in precipitation from one crop to another affected the amount of protein in all the cultivars, the main source of chemical compounds for the production of $\gamma$-PGA.

Water stress caused by scarcity can reduce the protein content of soybeans by $16 \%$ and lipids by $25 \%{ }^{34}$. A comparison of soybean cultivars from the 2015 and 2016 crops revealed differences in some parameters (Table 3). The SSF experiments were carried out with three replicates. The data were represented as means \pm standard deviation. The level of significance of the differences was evaluated by means of the $t$ test. An analysis of variance was performed using ANOVA procedures. The level of significance was set at $\mathrm{p}<0.05$.

From 2015 to 2016, the protein content increased by $25.8 \%$ in the BRS 360 RR cultivar, by $9.6 \%$ in the BRS 232 cultivar, and by $5.6 \%$ in the BRS 1001 IPRO cultivar. Although the soybean protein content is genetically determined, environmental factors can cause changes in nitrogen availability during grain formation ${ }^{35}$. Specht ${ }^{36}$ reported that soil irrigation has a positive effect on soybean protein content, and that severe droughts can cause the protein content to decrease. Soil water stress causes the proteins in soybean seeds to decrease during the stage of reproductive growth ${ }^{37}$. Pipolo ${ }^{38}$ stated that rainfall during the grain development stage, more than changes in temperature, explains differences in protein content. Therefore, changes in this parameter may be linked to water stress in this plant species. On the other hand, the proximate composition depends basically on genetic characteristics (type of cultivar), climate and regional conditions, varying according to the crop ${ }^{39-41}$.

Solid-state fermentation with $B$. licheniformis was performed using the three soybean cultivars of the 2015 and 2016 crops (Fig. 4). From the cultivars of the 2015 crop - BRS 232, BRS 360 RR, and BRS $1001 \mathrm{IPRO}-0.731 \mathrm{~g} \mathrm{~L}^{-1}, 0.643 \mathrm{~g} \mathrm{~L}^{-1}$, and $0.898 \mathrm{~g} \mathrm{~L}^{-1}$ of $\gamma$-PGA, respectively, were produced. From the 2016 crop, $1120.2 \mathrm{mg} \mathrm{L} \mathrm{L}^{-1}$ of $\gamma$-PGA was produced from the cultivar BRS 232, while $1.112 \mathrm{~g} \mathrm{~L}^{-1}$ and $1.177 \mathrm{~g} \mathrm{~L}^{-1}$, respectively, were produced from the cultivars BRS $360 \mathrm{RR}$ and BRS 1001 IPRO.

The cultivars BRS 232 and 360 RR showed a statistically significant difference in means $(p<0.05)$ between crops and cultivars. The means between the cultivars of crop 2016 were statistically equal, but the BRS 1001 IPRO cultivar was the one that presented the highest average production of $\gamma$-PGA. Crop 2016 cultivars showed greater potential as a substrate for solid-state fermentation (SSF), as they had a higher protein content, which is desirable in $\gamma$-PGA production. Although the microorganisms use glutamic acid as monomers to polymerize $\gamma$-PGA, the higher amount of total protein found in this study also indicated the greater pres- 


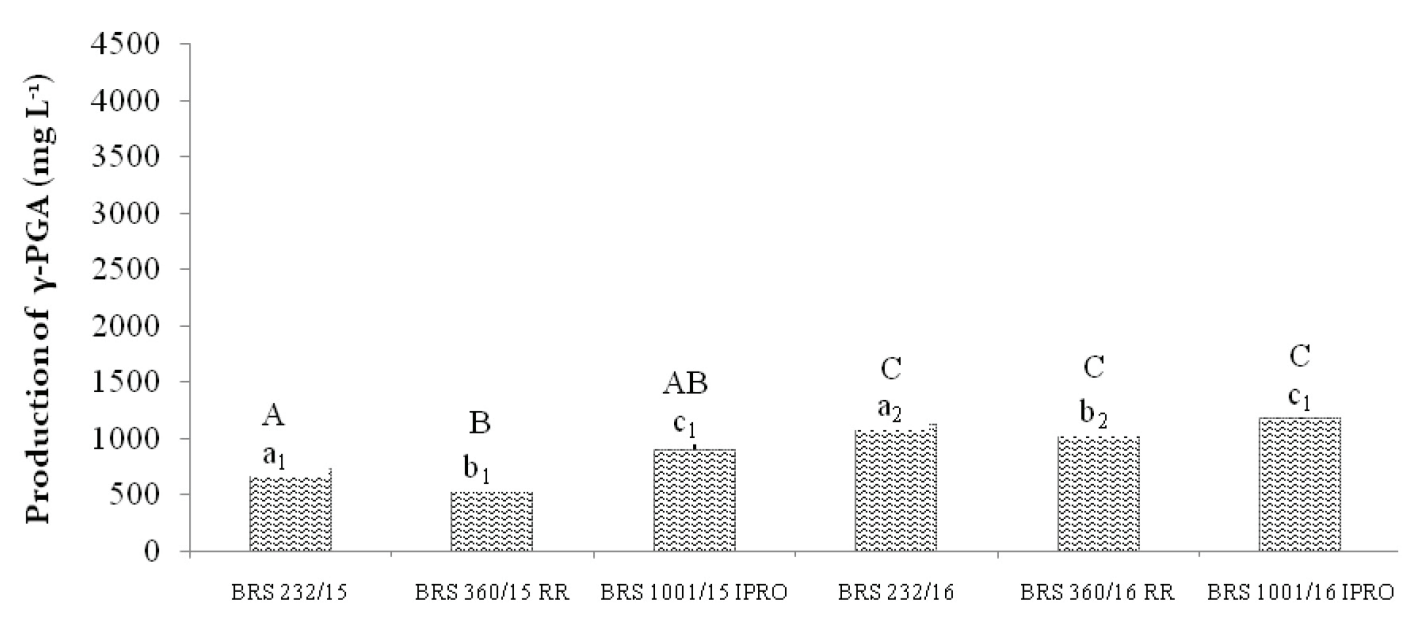

Soybean cultivars/crops

Fig. 4 - Production of $\gamma$-PGA by Bacillus licheniformis on different soybean cultivars from the 2015 and 2016 crops. All the data are presented as means \pm standard deviation. Lower case letters indicate a relationship between the means of the cultivars in the two crops, while the different numbers indicate statistically significant differences $(p<0.05)$. Different capital letters indicate statistically significant differences $(p<0.05)$ between the means of the different cultivars in the same crop.
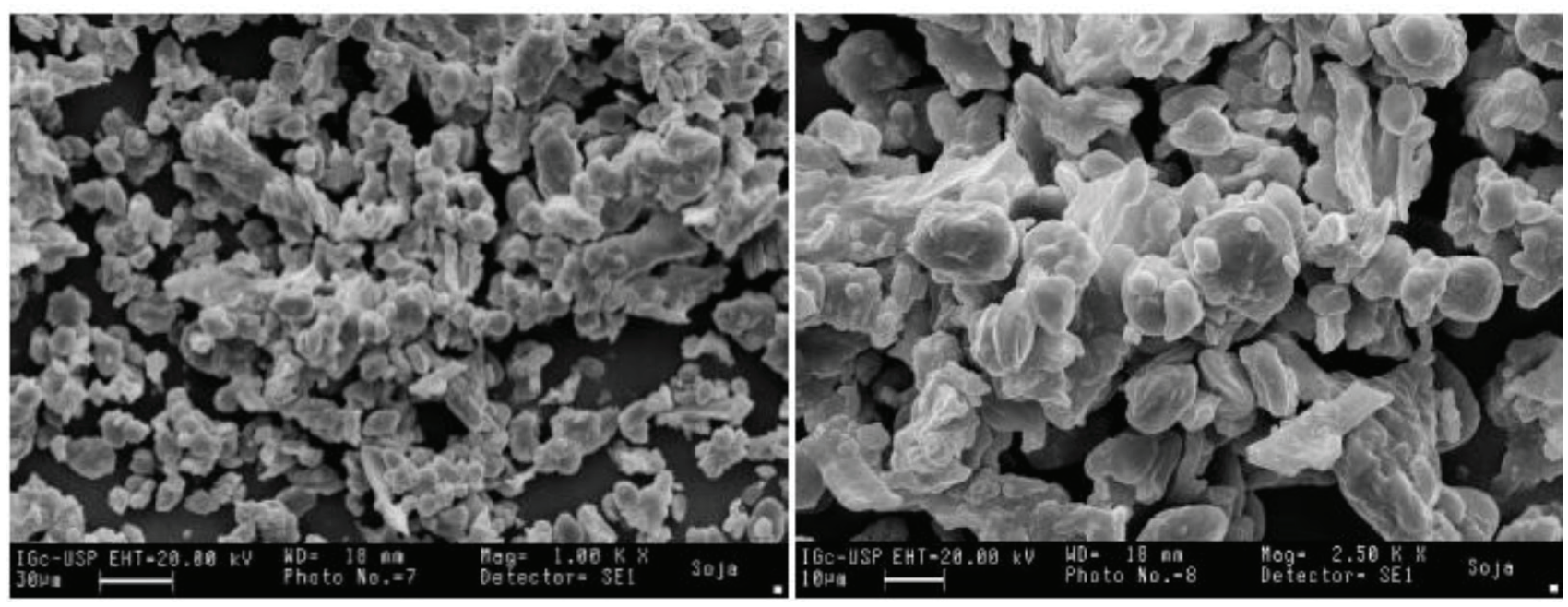

Fig. 5 - SEM images of soybean BRS 1001 IPRO (1000 and 2500X magnification)

ence of this amino acid and others that indirectly influence the production of $\gamma$-PGA, such as the amino acid alanine ${ }^{42}$.

To determine whether the soybean's physical structure affects the production of biopolymer, the BRS 1001 IPRO cultivar (Fig. 5) was milled to change the grain structure. The processed grains, i.e., fine, medium, and coarse fractions, produced $1.939 \mathrm{~g} \mathrm{~L}^{-1}, 2.253 \mathrm{~g} \mathrm{~L}^{-1}$ and $2.722 \mathrm{~g} \mathrm{~L}^{-1}$ of biopolymer, respectively (Fig. 6). These biopolymer yields show a statistically significant difference in means $(p<0.05)$ when compared to those obtained with the whole grains of the same soybeans and soybean crop.

Milling the soybeans increased the $\gamma$-PGA production in all the particle sizes when compared to the whole grains. The external protective layer of the beans was completely broken by milling, expos- ing their internal content. With the nutrients made widely available to microorganisms, biopolymer production had intensified. However, the particle size interfered with fermentation. The production of $\gamma$-PGA was lowest with the fine fraction, followed by the medium and coarse fractions. Although smaller particles have larger surface area, they cause the material to become compacted during fermentation, reducing the aeration of the entire content and the production of biopolymer. Larger particle sizes also provide greater aeration during fermentation, as observed in the medium and coarse fractions. The fine and medium fractions showed a statistically significant difference in means $(\mathrm{p}<0.05)$ when compared to the coarse fraction.

Notwithstanding the difference in results in the two fermentation processes, $\mathrm{SmF}$ and SSF, both 


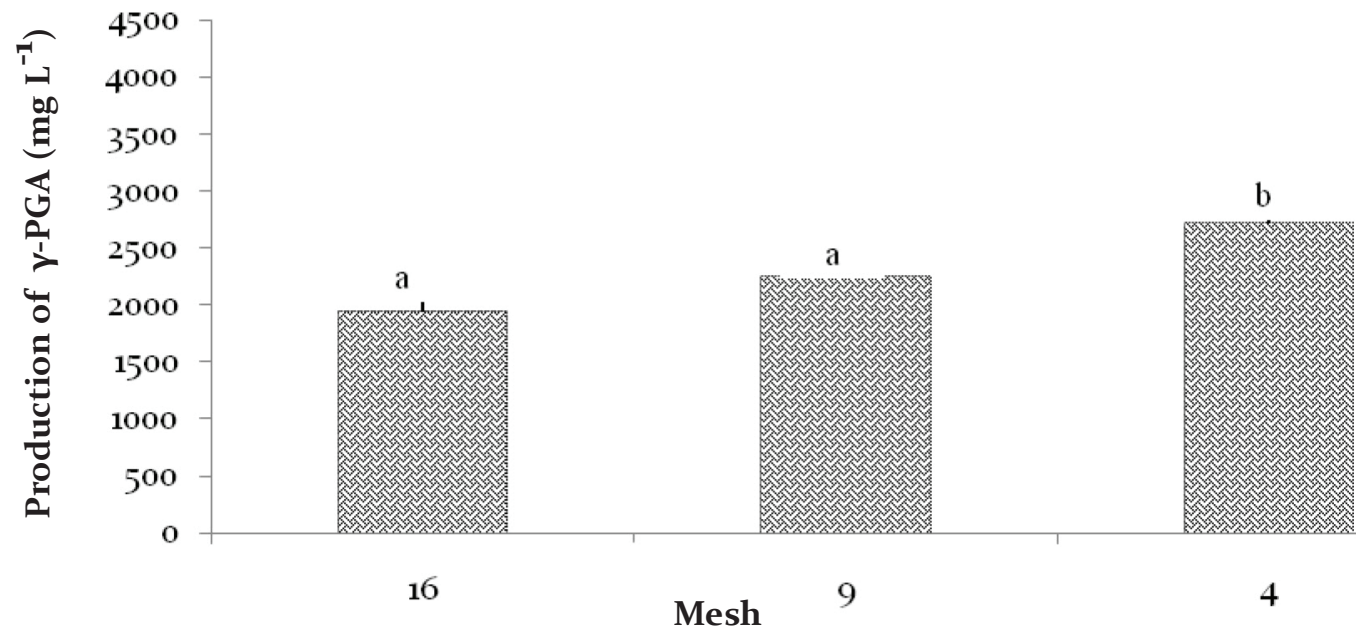

Fig. 6 - Production of $\gamma$-PGA by Bacillus licheniformis on substrate (BRS 1001 IPRO, 2016 crop) with different particle sizes. All the data are presented as means \pm standard deviation and the different letters indicate statistically significant differences ( $<<0.05)$.

Table 4-CHN content of soybean grain, standard $\gamma-P G A$ and $\gamma$-polyglutamic acid after extraction in SSF

\begin{tabular}{lcc|c|c}
\hline \multicolumn{1}{c|}{ Sample } & $\mathrm{C} / \%$ & $\mathrm{H} / \%$ & $\mathrm{~N} / \%$ & $\mathrm{C} / \mathrm{N}$ \\
\hline soybean & 47.06 & 7.17 & 7.18 & 6.55 \\
$\gamma$-PGA (SSF) & 48.03 & 7.92 & 6.85 & 7.01 \\
standard $\gamma$-PGA & 44.04 & 6.93 & 6.92 & 6.36 \\
\hline
\end{tabular}

processes required constant aeration. High oxygen ratios resulted in greater production of $\gamma$-PGA, and the same applies to the ideal amount of available nutrients in both processes.

\section{Characterization by elemental analysis and FTIR}

Table 4 presents the results of the elemental analysis of carbon, hydrogen, and nitrogen $(\mathrm{CHN})$, the materials of this study. The $\mathrm{CHN}$ results indicate very similar nitrogen/carbon values for standard $\gamma$-PGA and soybean grains. As can be seen, the carbon/nitrogen ratio for the reference $\gamma$-PGA and for the $\gamma$-PGA extracted from soybean grains is 7.96, which is consistent with the composition of the $\gamma$-PGA molecule. Considering that the formula of $\gamma$-PGA is $\left(\mathrm{C}_{5} \mathrm{H}_{6} \mathrm{NO}_{3}\right) \mathrm{Na}$ and based only on the monomer $\mathrm{C}_{5} \mathrm{H}_{6} \mathrm{NO}_{3}$, the $\gamma$-PGA extracted from SSF contained $50.33 \%$ of $\mathrm{C}, 7.27 \%$ of $\mathrm{H}, 6.32 \%$ of $\mathrm{N}$, and $36.08 \%$ of $\mathrm{O}$ (Table 5). In a typical elemental

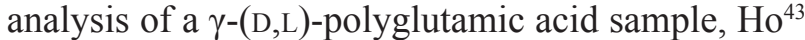
found that purified $\gamma$-PGA contained $46.51 \%$ of $\mathrm{C}$, $5.43 \%$ of $\mathrm{H}$, and $10.85 \%$ of $\mathrm{N}$.

Table 5 lists the results of the FTIR analysis of soybean grain, standard $\gamma$-PGA, SSF and SmF. The peaks of the standard $\gamma$-PGA and $\gamma$-PGA produced by $B$. licheniformis spectra are similar, given that the samples have the same composition because natto is produced from fermented soybeans, i.e., it is composed of soybeans, $\gamma$-PGA, and levan polysaccharide. The diagnostic region of the soybean and other solutions spectra shows peaks at 1640 $\mathrm{cm}^{-1}$. These peaks correspond to $\mathrm{C}-\mathrm{H}$ stretching with $\mathrm{sp}^{3}$ hybridization, and the peaks originate from symmetric and asymmetric stretching of $\mathrm{C}-\mathrm{H}$. The spectra of soybeans and other products also show peaks at around $1450 \mathrm{~cm}^{-1}$, which represent the $\mathrm{C}=\mathrm{O}$ functional group. The soybean, SSF and $\gamma$-PGA spectra show strong peaks at around $1640 \mathrm{~cm}^{-1}$, which is characteristic of the amide I group, $\mathrm{N}-\mathrm{H}$ bending band. These spectra also show a broad absorption band near $3400 \mathrm{~cm}^{-1}$, which corresponds to the $\mathrm{O}-\mathrm{H}$ bond of an alcohol functional group. Mill$\mathrm{er}^{44}$ used FTIR to analyze soybean grains, and based on the characteristic peaks of each component, de-

Table 5 - FTIR absorption peaks $\left(\mathrm{cm}^{-1}\right)$ for standard $\gamma$-PGA used as reference material, and after the process of $\gamma$-PGA extraction from SSF and SmF

\begin{tabular}{l|c|c|c|c|c|c}
\hline \multicolumn{1}{c|}{ Sample } & Amide I & Amide II & $\mathrm{C}=\mathrm{O}$ & $\mathrm{C}-\mathrm{N}$ & $\mathrm{N}-\mathrm{H}$ & $\mathrm{O}-\mathrm{H}$ \\
\hline Soybeans & 1643.32 & 1547.43 & 1401.74 & 1143.1 & 699.17 & 3419.56 \\
Standard $\gamma$-PGA & 1643.28 & 1556.75 & 1405.23 & 1163.09 & 704.38 & 3436.71 \\
$\gamma$-PGA (SSF) & 1643.04 & 1554.47 & 1401.89 & 1159.91 & 699.81 & 3428.01 \\
$\gamma$-PGA (SmF) & 1643.73 & 1550.02 & 1417.46 & 1211.02 & 697.26 & 3446.21 \\
\hline
\end{tabular}


termined the presence of the groups: amide I at $1650 \mathrm{~cm}^{-1}$ associated with protein, lipid ester at $1545 \mathrm{~cm}^{-1}$, and carbohydrates in the region of 1200 to $900 \mathrm{~cm}^{-1}$. These authors stated that the amount and configuration of proteins varied along the cotyledon, as well as the amount of lipids and carbohydrates $^{44,45}$. An FTIR analysis of the soybeans revealed the presence of the amide I group at 1643.32 $\mathrm{cm}^{-1}$ associated with protein, and lipid ester at $1547.43 \mathrm{~cm}^{-1}$.

The FTIR absorption bands for standard $\gamma$-PGA in $\mathrm{KBr}$ pellets are: amide $\mathrm{I}, \mathrm{N}-\mathrm{H}$ bending band at $1643 \mathrm{~cm}^{-1}$; amide II, stretching band at $1456 \mathrm{~cm}^{-1}$; $\mathrm{C}=\mathrm{O}$ symmetric stretching band at $1445 \mathrm{~cm}^{-1} ; \mathrm{C}-\mathrm{N}$ stretching band at $1263 \mathrm{~cm}^{-1} ; \mathrm{N}-\mathrm{H}$ out of plane bending band at $667 \mathrm{~cm}^{-1}$; and $\mathrm{O}-\mathrm{H}$ stretching band at $3436 \mathrm{~cm}^{-1}$.

\section{Conclusions}

One of the goals of this work was to test the performance of the airlift bioreactor, which is easy to use and inexpensive, in the production of $\gamma$-PGA from $B$. licheniformis in a medium containing a low down combination of carbon and nitrogen nutrients. The airlift bioreactor tests showed promising results, since the system enabled the constant movement of the medium without the risk of the cells undergoing shear stress. Moreover, viscosity in this system did not increase, which can be explained by the addition of glycerol with $B$. licheniformis. The tests carried out in the airlift bioreactor showed a maximum productivity of $0.789 \mathrm{~g} \mathrm{~L}^{-1} \mathrm{~h}^{-1}$ with $B$. licheniformis and yield of $0.4 \mathrm{~g} \mathrm{~g}^{-1}$.

The genetic variation of soybean cultivars did not influence the protein concentration. However, the increase in rainfall during the growing period (2016) resulted in a higher protein content in the soybeans. In this study, the cultivars BRS 232, BRS $360 \mathrm{RR}$, and BRS 1001 IPRO from the $2016 \mathrm{crop}$ showed a greater potential as a substrate in SSF because of their high total protein content, which resulted in a higher yield of $\gamma$-PGA. The production of biopolymer was influenced by the physical structure of soybeans. The use of milled soybeans increased the $\gamma$-PGA production yield, which was highest with the coarse fraction. Milling the soybeans increased the availability of nutrients to microorganisms, and the coarse fraction reduced the impact of compaction, enabling aeration of the substrate. The initial moisture content and volume of inoculum were considered significant factors for the production of $\gamma$-PGA. The optimization of significant factors increased the $\gamma$-PGA production yield to $4.4 \mathrm{~g} \mathrm{~L}^{-1}$.

\section{ACKNOWLEDGEMENTS}

This research was financed by the Brazilian research funding agencies $\mathrm{CNPq}$ (National Council for Scientific and Technological Development, Grant $n^{\circ}$ 400040/2016-6), FAPESP (São Paulo Research Foundation, Grant $n^{\circ}$ 2015/02650-8), and IGTPAN - Granado Polyacrylonitrile Technology Institute.

\section{References}

1. Buescher, J. M., Margaritis, A., Microbial biosynthesis of polyglutamic acid biopolymer and applications in the biopharmaceutical, biomedical and food industries, Crit. Rev. Biotechnol. 27(1) (2007) 1.

doi: https://doi.org/10.1080/07388550601166458

2. Candela, T., Fouet, A., Poly-gamma-glutamate in bacteria, Mol. Microbiol. 60 (2006) 1091

doi: https://doi.org/10.1111/j.1365-2958.2006.05179.x

3. Oh, S. M., Jang, E. K., Seo, J. H., Ruy, M. J., Lee, S. P., Characterization of y-polyglutamic acid produced from the solid-state fermentation of soybean milk cake using Bacillus sp., Food Sci. Biotechnol. 16(4) (2007) 509.

doi: https://www.dbpia.co.kr/journal/articleDetail?nodeId=NODE01730682

4. Xu, J., Chen, $S$., Yu, Z., Optimization of process parameters for poly $\gamma$-glutamate production under solid state fermentation from Bacillus subtilis CCTCC202048, Process. Biochem. 40(9) (2005) 3075. doi: https://doi.org/10.1016/j.procbio.2005.03.011

5. Chen, X., Chen, S., Sun, M., Yu, Z., High yield of poly- $\gamma-$ glutamic acid from Bacillus subtilis by solid-state fermentation using swine manure as the basis of a solid substrate, Bioresour. Technol. 96(17) (2005) 1872. doi: https://doi.org/10.1016/j.biortech.2005.01.033

6. Chen, X., Chen, S., Sun, M., Yu, Z., Medium optimization by response surface methodology for poly- $\gamma$-glutamic acid production using dairy manure as the basis of solid substrate, Appl. Microbiol. Biotechnol. 69 (2005) 390. doi: https://doi.org/10.1007/s00253-005-1989-z

7. Campos, V., Fernandes, A. R. A. C., Medeiros, T. A. M., Andrade, E. L., Physicochemical characterization and evaluation of PGA bioflocculant in coagulation-flocculation and sedimentation processes, J. Environ. Chem. Eng. 4(4) (2016) 3753.

doi: https://doi.org/10.1016/j.jece.2016.08.011

8. Shih, I. L., Van, Y. T., The production of poly-( $\gamma$-glutamic acid) from microorganisms and its various applications, Bioresour. Technol. 79(3) (2001) 207. doi: https://doi.org/10.1016/S0960-8524(01)00074-8

9. Yang, X., Preparation and characterization of $\gamma$-poly(glutamic acid) copolymer with glycol diglycidyl ether, Procedia. Environ. Sci. 8 (2011) 11. doi: https://doi.org/10.1016/j.proenv.2011.10.004

10. Campos, V., Domingos, J. M. F., Anjos, D. N., Lira, V. S., Study of fluvial water treatability using $\gamma$-polyglutamic acid based biopolymer coagulant, An. Acad. Bras. Cienc. 91(3) (2019) 1 . doi: https://doi.org/10.1590/0001-3765201920190051

11. Bajaj, I. B., Singhal, R. S., Poly (glutamic acid) - An emerging biopolymer of commercial interest, Bioresour. Technol. 102(10) (2011) 5551 . doi: https://doi.org/10.1016/j.biortech.2011.02.047 
12. Shih, I. L., Van, Y. T., Chang, Y. N., Application of statistical experimental methods to optimize production of poly (-glutamic acid) by Bacillus licheniformis CCRC 12826, Enzyme Microb. Technol. 31(3) (2002) 213 doi: https://doi.org/10.1016/S0141-0229(02)00103-5

13. Morelli, C. F., Calvio, C., Biagiotti, M., Speranza, G., $\mathrm{pH}-$ Dependent hydrolase, glutaminase, transpeptidase and autotranspeptidase activities of Bacillus subtilis $\gamma$-glutamyltransferase, FEBS J. 281(1) (2014) 232. doi: https://doi.org/10.1111/febs.12591

14. Wu, Q., Xu, H., Shi, N. N., Yao, J., Li, S., Ouyang, P., Improvement of poly(gammaglutamic acid) biosynthesis and redistribution of metabolic flux with the presence of different additives in Bacillus subtilis CGMCC 0833, Appl. Microbiol. Biotechnol. 79(4) (2008) 527. doi: https://doi.org/10.1007/s00253-008-1462-x

15. Zhou, M., Zeng, D., Ni, X., Tu, T., Yin, Z., Pan, K., Jing, B., Effects of Bacillus licheniformis on the growth performance and expression of lipid metabolism-related genes in broiler chickens challenged with Clostridium perfringensinduced necrotic enteritis, Lipids Health. Dis. 15(48) (2016) 1 doi: https://doi.org/10.1186/s12944-016-0219-2

16. Tucker, G. A., Woods, L. F. J., Enzymes in food processing. 2nd ed. London: Aspen Publ., 1995, pp 319.

17. Qiu, Y., Zhang, J., Li, L., Wen, Z., Nomura, C. T., Wu, $S$., Chen, S., Engineering Bacillus licheniformis for the production of meso-2,3-butanediol, Biotechnol. Biofuels 9 (2016) 117. doi: https://doi.org/10.1186/s13068-016-0522-1

18. Cladera-Olivera, F., Caron, G. R., Brandelli, A., Bacteriocin production by Bacillus licheniformis strain P40 in cheese whey using response surface methodology, Biochem. Eng. J. 21(1) (2004) 53. doi: https://doi.org/10.1016/j.bej.2004.05.002

19. Trinder, $P$., Determination of glucose in blood using glucose oxidase with an alternative oxygen acceptor, Ann. Clin. Biochem. 6 (1969) 24 doi: https://doi.org/10.1177/000456326900600108

20. Huang, H.-S., Yoshida, T., Meng, Y., Kabashima, T., Ito, K., Nishiya, Y., Kawamura, Y., Yoshimoto, T., Purification and characterization of thermostable glycerol kinase from Thermus flavus, J. Ferment. Bioeng. 83(4) (1997) 328. doi: https://doi.org/10.1016/S0922-338X(97)80137-7

21. Kanno, A., Takamatsu, H., Determination of polyglutamic acid in "Natto" using cetyltrimethylammonium bromide (Studies on "Natto" part V), Nippon Shokuhin Kagaku Kogaku Kaishi, J. Jpn. Soc. Food Sci. Technol. 42(11) (1995) 878. doi: https://doi.org/10.3136/nskkk.42.878

22. Firestone, D., Official methods and recommended practices of the american oil chemists society. 6. ed. Urbana: AOCS, Ilinois, 2014, pp 1200.

23. Zenebon, O., Pascuet, N. S., Métodos físico-químicos para análise de alimentos. 4. ed. Brasília: Ministério da Saúde/ ANVISA São Paulo: Instituto Adolfo Lutz, 2005, pp $522-$ 532.

24. Rossi, M. J., Nascimento, F., Giachini, A., Oliveira, V. Furigo $J r$, A., Airlift bioreactor fluid-dynamic characterization for the cultivation of shear stress sensitive microorganisms, J. Adv. Biotechnol. 5(2) (2016) 639. doi: https://doi.org/10.24297/jbt.v5i2.4846

25. Kumar, R., Pal, P., Fermentative production of poly ( $\gamma$-glutamic acid) from renewable carbon source and downstream purification through a continuous membrane-integrated hybrid process, Bioresour. Technol. 177 (2015) 141. doi: https://doi.org/10.1016/j.biortech.2014.11.078
26. Yoon, H. Y., Hwan, Do, J., Yup Lee, S., Chang, H. N., Production of poly- -glutamic acid by fed-batch culture of Bacillus licheniformis, Biotechnol. Lett. 22 (2000) 585. doi: https://doi.org/10.1023/A:1005625026623

27. Rossi, J. M., Souza, J., Oliveira, V., Inoculum production of the ectomycorrhizal fungus Pisolithus microcarpus in an airlift bioreactor, Appl. Microbiol. Biotechnol. 59(2) (2002) 175 . doi: https://doi.org/10.1007/s00253-002-0999-3

28. Kiuchi, K., Watanabe, S., Industrialization of Japanese natto. In: Steinkraus, K. H. (Ed.), Industrialization of indigenous fermented foods, second ed., Marcel Dekker, New York, 2004 pp. 193-245.

29. Bajaj, I. B., Singhal, R. S., Enhanced Production of poly ( $\gamma$-glutamic acid) from Bacillus licheniformis NCIM 2324 by using metabolic precursors, Appl. Biochem. Biotechnol. 159(1) (2009) 133. doi: https://doi.org/10.1007/s12010-008-8427-5

30. Goto, A., Kunioka, M., Biosynthesis and hydrolysis of poly ( $\gamma$-glutamic acid) from Bacillus subtilis IFO 3335, Biosci. Biotechnol. Biochem. 56(7) (1992) 1031. doi: https://doi.org/10.1271/bbb.56.1031.

31. Zeng, W., Chen, G. G., Zhang, Y. K., Wu, K. Y., Liang, Z. $Q$., Studies on the UV spectrum of poly ( $\gamma$-glutamic acid) based on development of a simple quantitative method, Int J. Biol. Macromol. 51(1) (2012) 83. doi: https://doi.org/10.1016/j.ijbiomac.2012.04.005

32. Hsueh, Y.-H., Huang, K.-Y., Kunene, S. C., Lee, T.-Y., Poly$\gamma$-glutamic acid synthesis, gene regulation, phylogenetic relationships, and role in fermentation, Int. J. Mol. Sci. 18(12) (2017) 2644 doi: https://doi.org/10.3390/ijms18122644

33. $W u, Q ., X u, H$. , Liang, J., Yao, J., Contribution of glycerol on production of poly $(\gamma$-glutamic acid) in Bacillus subtilis NX-2, Appl. Biochem. biotechnol. 160(2) (2010) 386. doi: https://doi.org/10.1007/s12010-008-8320-2

34. Rotundo, J. L., Westgate, M. E., Meta-analysis of environmental effects on soybean seed composition, Field. Crops Res. 110(2) (2009) 147. doi: https://doi.org/10.1016/j.fcr.2008.07.012

35. Hayati, R., Egli, D. B., Crafts-Brandner, S. J., Carbon and nitrogen supply during seed filling and leaf senescence in soybean, Crop Sci. 35(4) (1995) 1063. doi: https://doi.org/10.2135/cropsci1995.0011183X003500040024x 36. Specht, J. E., Chase, K., Macrander, M., Graef, G. L., Chung, J., Markwell, J. P., Germann, M., Orf, J. H., Lark, $K$. $G$., Soybean response to water: A QTL analysis of drought tolerance, Crop Sci. 41(2) (2001) 493. doi: https://doi.org/10.2135/cropsci2001.412493x

37. Wijewardana, C., Reddy, K. R., Bellaloui, N., Soybean seed physiology, quality, and chemical composition under soil moisture stress, Food Chem. 278 (2019) 92. doi: https://doi.org/10.1016/j.foodchem.2018.11.035

38. Pipolo, A. E., Sinclair, T. R., Camara, G. M. S., Effects of temperature on oil and protein concentration in soybean seeds cultured in vitro, Ann. Appl. Biol. 144(1) (2004) 71. doi: https://doi.org/10.1111/j.1744-7348.2004.tb00318.x

39. Karr-Lilienthal, L. K., Grieshop, C. M., Merchen, N. R., Mahan, D. C., Fahey, G. C., Chemical composition and protein quality comparisons of soybean and soybean meals from five leading soybean-producing countries. Agric. Food Chem. 52(20) (2004) 6193. doi: https://doi.org/10.1021/jf049795+ 
40. Mertz, L. M., Henning, G. A., Cruz, H. L., Meneghello, G. E., Ferrari, C. S., Zimmer, P. D., Structural differences between soybean seeds coat with contrasting permeability, Rev. Bras. Sementes. 31(1) (2009) 23.

doi: https://doi.org/10.1590/S0101-31222009000100003

41. Barion, G., Hewidy, M., Mosca, G., Vamerali, T., Intraspecific variability for soybean cotyledon isoflavones in different cropping and soil conditions. Eur. J. Agronomy. 33(2) (2010) 63.

doi: https://doi.org/10.1016/j.eja.2010.03.002

42. Sirisansaneeyakul, S., Cao, M., Kongklom, N., Chuensangjun, C., Shi, Z., Chisti, Y., Microbial production of poly- $\gamma$-glutamic acid, World J. Microbiol. Biotechnol. 33(173) (2017) 1.

doi: https://doi.org/10.1007/s11274-017-2338-y
43. Ho, G.-H., Ho, T.-I., Hsieh, K.-H., Su, Y.-C., Lin, P.-Y., Yang, J., Yang, K.-H., Yang, S.-C., $\gamma$-Polyglutamic acid produced by Bacillus Subtilis (Natto): Structural characteristics, chemical properties and biological functionalities, J. Chinese Chem. Soc. 53(6) (2006) 1363. doi: https://doi.org/10.1002/jccs.200600182

44. Miller, S. S., Pietrzak, L. N., Wetzel, D. L. Preparation of soybean seed samples for FT-IR microspectroscopy, Biotech. Histochem. 80(3-4) (2005) 117. doi: https://doi.org/10.1080/10520290500166282

45. Zhu, B., Li, J., He, Y., Yoshie, N., Inoue, Y., Hydrogen-bonding interaction and crystalline morphology in the binary blends of poly( $\varepsilon$-caprolactone) and polyphenol catechin, Macromol. Biosci. 3(11) (2003) 684.

doi: https://doi.org/10.1002/mabi.200350034 